\title{
MONARTICULAR, NON-INFECTIVE SUBACUTE ARTHRITIS OF THE STERNO-CLAVICULAR JOINT
}

\author{
R. A. BRemner, York, ENGland \\ Formerly Senior Orthopaedic Registrar, The Middlesex Hospital, London
}

The purpose of this paper is to describe a monarticular, non-infective subacute arthritis of the sterno-clavicular joint which occurs in middle-aged women. The clinical features are so typical and the course is so predictable that this condition can be considered a specific entity.

This report is based on twelve patients. Seven were studied by the author throughout their illness; the other five were found by a search of past records and had been diagnosed in various ways at the time of operation, but the clinical and radiographic records, with a re-examination of the pathological material removed at operation, leave no doubt that these patients were suffering from the same condition. It has been possible to follow up the five earlier patients; the average time since their operation was ten years and the longest twenty years.

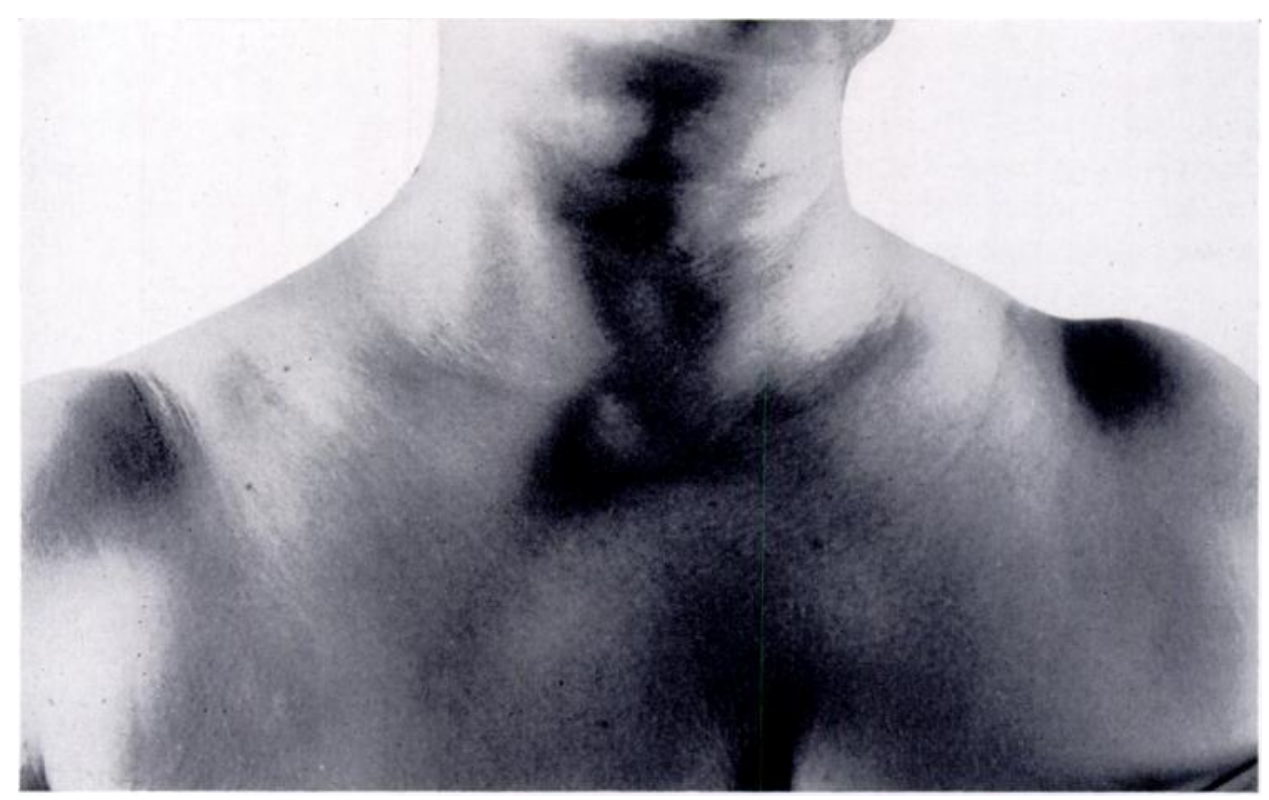

FIG. 1

The clinical appearance of the swelling of the right sterno-clavicular joint is shown in this photograph.

The patients were all women, between thirty-four and sixty-three years of age, the average being fifty-six years. In eleven right-handed patients the right sterno-clavicular joint was affected and the left in one who was left handed.

\section{CLINICAL OBSERVATIONS}

These were similar in all patients and a general description will suffice. A woman, aged fifty to sixty years old, complains of the gradual onset of a lump over the sterno-clavicular joint, usually the right, with slight aching in the swelling as well as along the clavicle and in the 
shoulder, which is aggravated by the use of the arm. There is no history of injury, and no evidence of other joint involvement or constitutional illness can be found.

On examination there is a slightly tender, soft and sometimes fluctuant swelling of the affected sterno-clavicular joint (Fig. 1). There is no increase in heat. There is no abnormality of the shoulder except a slight limitation of movement because of discomfort. Examination of the blood shows a normal erythrocyte sedimentation rate and white cell count, and the Wassermann reaction is negative. The Rose-Waaler test (Waaler 1940; Rose, Ragan, Pearce and Lipman 1948) was negative when done in four patients during the "acute" phase.

Radiological changes-The sterno-clavicular joint may show juxta-articular rarefaction or, in 60 per cent of patients, actual erosion of the articular surface of the clavicle. Subluxation is never seen. Radiography of this joint is difficult, but the joint can be defined in oblique views and by tomography. Figures 2 and 3 show this erosion in radiographs taken by both methods.

Associated conditions-Two patients had mild diabetes and another, who was treated without operation, later developed a typical "de Quervain's disease" at the right wrist. The remainder were otherwise healthy.

\section{PATHOLOGY}

Observations at operation-The joint capsule is much thickened and distended by pinkish-grey granulation tissue and a variable amount of non-purulent fluid. There is partial or complete destruction of the intra-articular fibrocartilage and a variable degree of destruction and erosion of the joint surfaces.

Culture of joint tissues-The synovial fluid and tissues were always sterile on culture.

Histological observations-Material from all joints treated by operation has been re-examined. The general appearance is that of a "rheumatoid" condition. There is a villous hypertrophy and oedema of the synovia, in which are found lymphatic aggregations (Fig. 4). A vascular fibrous pannus covers part of the surface of the cartilage, which is destroyed to a varying degree (Fig. 5). Osteoarthritic changes are present but are much less conspicuous (Fig. 6).

\section{NATURAL HISTORY}

The swelling of the joint shows little change for a month or two and then it slowly subsides over a period of several more months. The symptoms generally disappear even though a quite obvious swelling remains. In nine months to one year resolution is almost complete although some palpable thickening, just visible on careful inspection, remains, probably permanently. In no patient has there been subsequent involvement of the other sternoclavicular joint; nor have any manifestations of generalised rheumatoid disease developed.

\section{MANAGEMENT}

Seven of the patients in this series were treated by operation largely because of doubt in the diagnosis. Six had a synovectomy and excision of the medial inch of the clavicle, and one had synovectomy alone. Because the nature of the condition was more clearly understood five of the more recent patients were treated without operation, and were given short-wave diathermy as a placebo.

\section{RESULTS}

The results of operation were good. At first there was usually considerable thickening of the area of operation, which took about two months to subside. There was no functional disability from the loss of the medial end of the clavicle, but some patients complained that the remainder was prominent. The five patients managed conservatively also did well; they lost their symptoms quite soon and the swelling subsided slowly. 


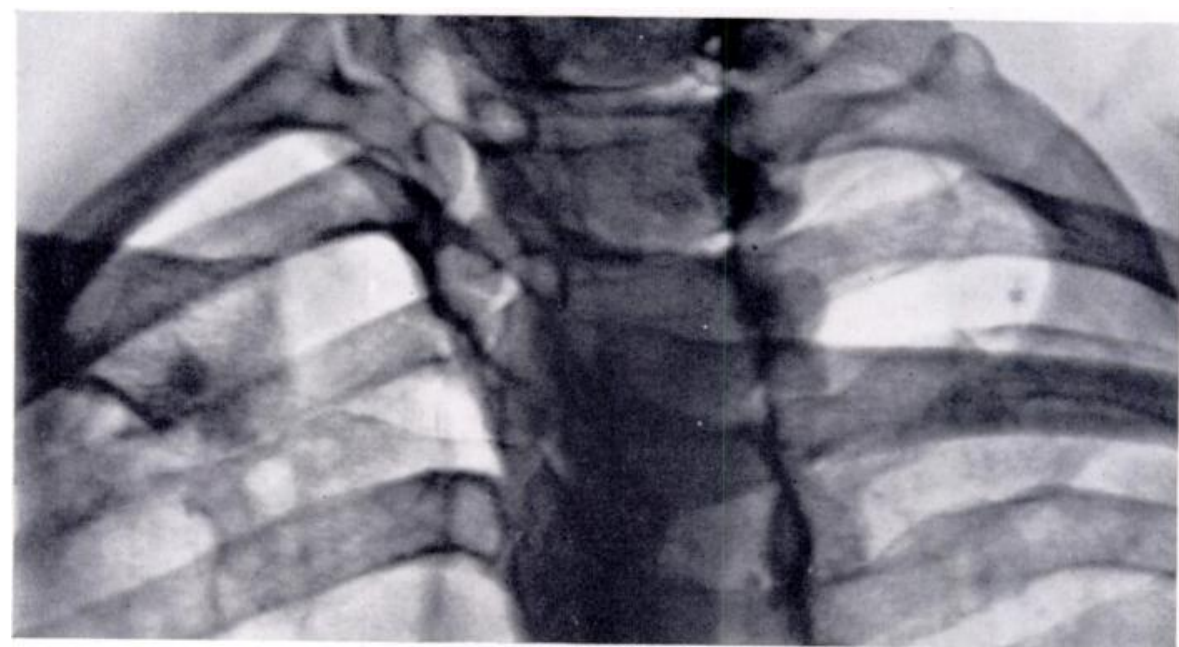

Fig. 2

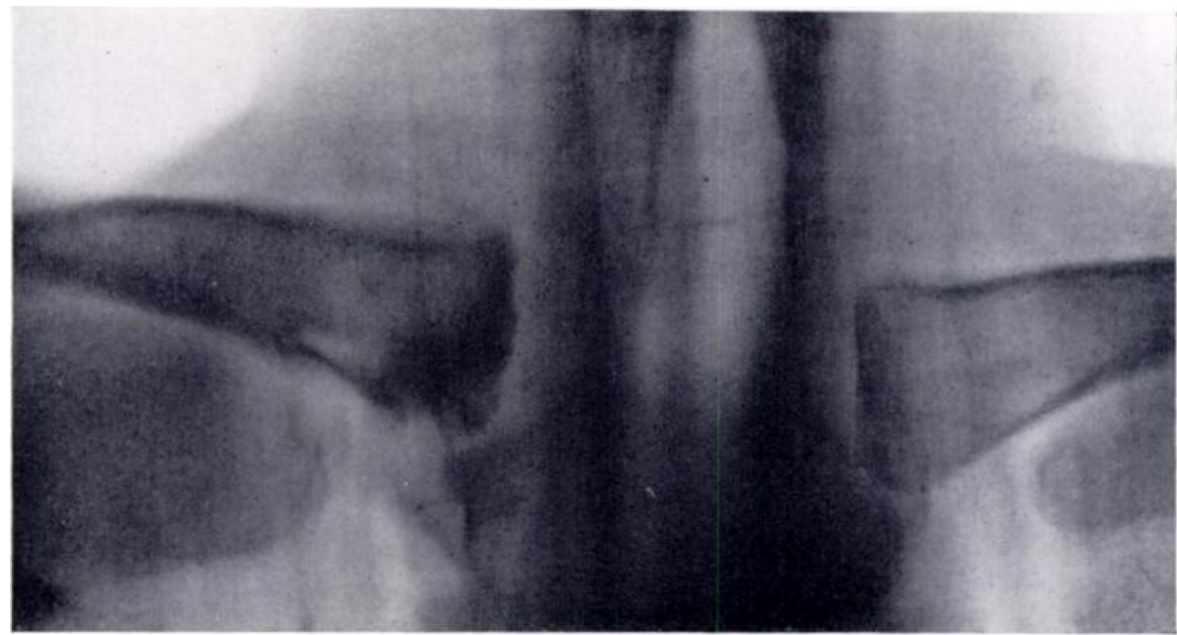

FIG. 3

The erosion of the medial end of the clavicle is well shown both in the oblique view (Fig. 2) and the tomograph (Fig. 3).

\section{DISCUSSION}

Histologically this condition appears to be rheumatoid arthritis in its broader sense. The microscopic appearances of the tissues in rheumatoid disease have been regarded by some as "virtually diagnostic" (Collins 1949), but there is no absolute diagnostic feature. It is essentially a combination of changes, with multiple joint involvement, that establishes the diagnosis. In the absence of the latter the histological appearances cannot be regarded as specific.

It is relevant. however, to consider the involvement of the sterno-clavicular joint in classical generalised rheumatoid arthritis. Figures are few. Monroe (1939) reported involvement of this joint in 0.5 per cent of patients with chronic generalised rheumatoid arthritis, and Master and Jaffe (1934) estimated its frequency in polyarticular rheumatoid arthritis of acute onset as 2 per cent. More recent authors (Arlet and Ficat 1958, Sokoloff and Gleason 1954) suggest, on scant published evidence, the much higher rate of 30 to 50 per cent. This difference is presumably because different criteria were used, the earlier writers referring to severe involvement, such as we are concerned with here, and the more recent authors accepting

VOL. $41 \mathrm{~B}$, No. 4, NOVEMBER 1959 
R. A. BREMNER

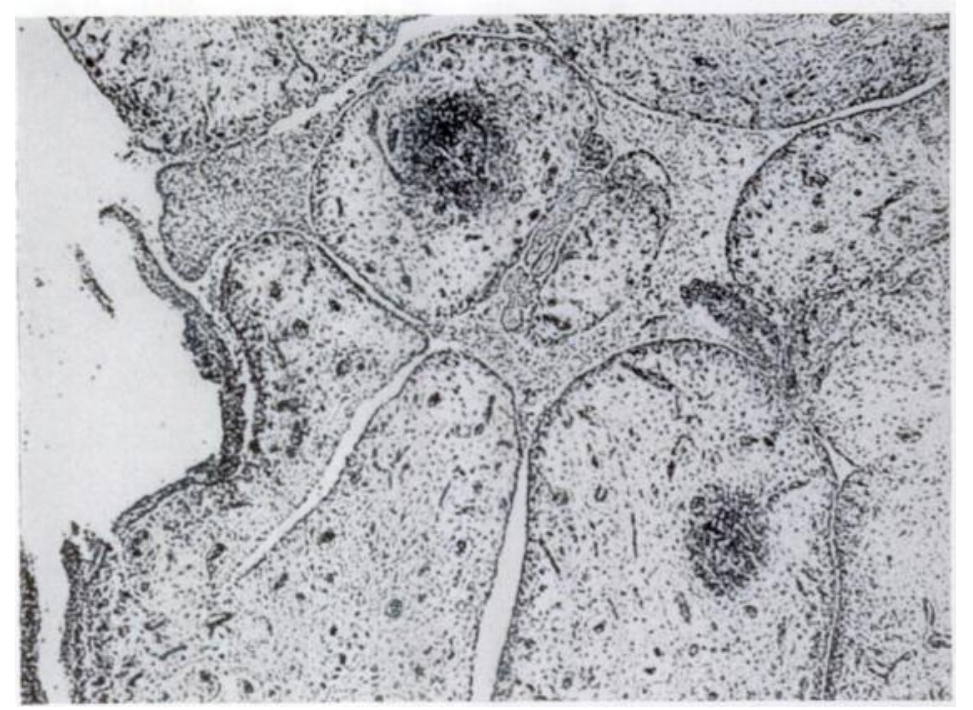

Fig. 4

A section of an affected joint to show the villous hypertrophy of the synovial tissues. $(\times 40$.)

Fici. 5

In this section the vascular fibrous pannus can be seen covering part of the articular cartilage. ( 33.)
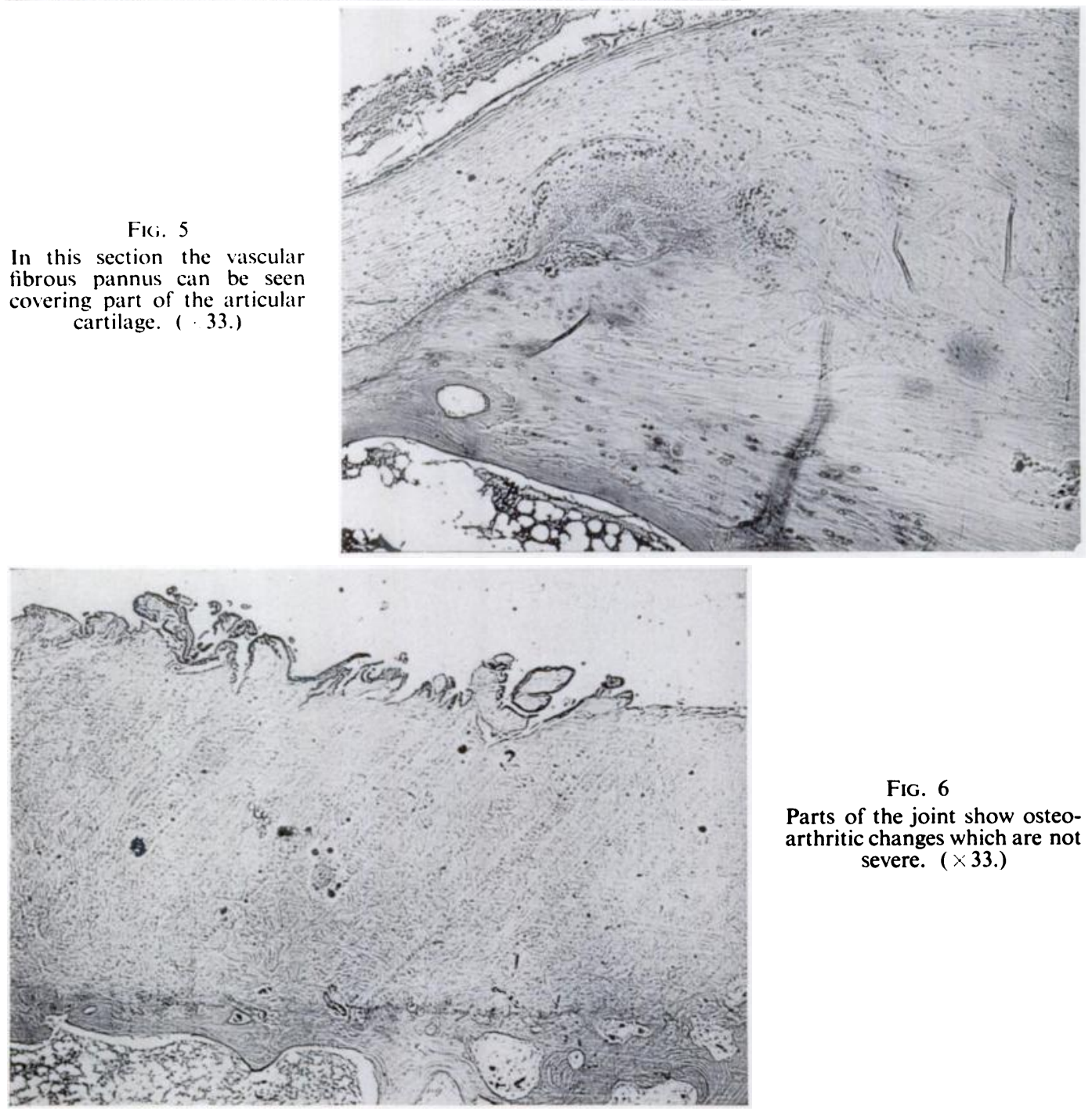

Fig. 6

Parts of the joint show osteoarthritic changes which are not severe. $(\times 33$. 
joint tenderness alone as sufficient evidence of the disease. It seems, therefore, that severe involvement of the sterno-clavicular joint in acute or chronic generalised rheumatoid arthritis is unusual although not unknown.

Rheumatoid disease may present in many atypical forms (Ropes and Bauer 1945), and, on occasion, as a monarticular affection, but the diagnosis can be firmly established only by the subsequent development-in at least a proportion of patients-of typical generalised rheumatoid disease. This did not occur in any patient in this series. The normal erythrocyte sedimentation rate and the negative results of other tests, of no significance in a single patient, as a whole add to the evidence that the condition we are considering is not a manifestation of rheumatoid disease.

Clinically osteoarthritis of the sterno-clavicular joint is not common, but Langen (1934) and Sokoloff and Gleason (1954) have shown that, in a routine microscopical examination of these joints obtained at necropsy, the early changes of osteoarthritis, while common by the age of twenty years, are always present by the age of fifty. It can be assumed, therefore, that the osteoarthritic changes seen in the joint material studied from patients in this series, who were in the sixth decade, were present before the onset of the pathological condition with which they presented.

Involvement of the right joint in the eleven right-handed patients and of the left in the only left-handed patient is interesting. but its significance, if any, is difficult to assess. It suggests that the greater use of the dominant limb plays a part in localising the disease process, but it must be assumed that it was acting on prepared ground.

In the light of present knowledge no firm conclusions can be reached concerning the etiology of this condition. Apart from a suggestive microscopic picture there is no evidence that it is an atypical variant of rheumatoid arthritis.

The author believes that this condition is by no means uncommon. but no previous description has been found in the literature. The advantage of recognising it-whether or not it may ultimately prove to be a specific entity-is that an excellent prognosis can be given because the condition does not appear to be a precursor of a generalised disease and runs a natural course towards resolution and recovery.

My thanks are due to Mr Philip Wiles for permission to publish this material from patients under his care, and also for his most helpful advice and criticism in preparation of this paper, and to Dr A. D. Thompson of the Bland Sutton Institute of Pathology for reporting on and photographing the histological material.

\section{REFERENCES}

Arlet, J., and Ficat, P. (1958): Osteo-arthritis of the Sterno-clavicular Joint. Annals of the Rheumatic Diseases, 17, 97.

Collins, D. H. (1949): The Pathology of Articular and Spinal Diseases, p. 174. London: Edward Arnold \& Co. LANGen, P. (1934): Untersuchungen über die Altersveränderungen und Abnutzungsercheinungen am Sternoclaviculargelenk. Virchows Archiv für pathologische Anatomie und Physiologie, 293, 381.

MASTER, A. M., and JAFF, H. L. (1934): The Heart in Rheumatic and Acute Rheumatoid (Infectious) Arthritis. Medical Clinics of North America, 18, 759.

Monroe, R. T. (1939): Chronic Arthritis. Chapter 15 in Oxford Medicine. Edited H. A. Christian. Vol. $4^{\text {ii }}, 391$. New York: Oxford University Press.

Ropes, M. W., and BaUer, W. (1945): Rheumatoid Arthritis: its Varied Clinical Manifestations. New England Journal of Medicine, 233, 592, 618.

Rose, M. H., Ragan, C., Pearce, E., and lipman, M. O. (1948): Differential Agglutination of Normal and Sensitized Sheep Erythrocytes by Sera of Patients with Rheumatoid Arthritis. Proceedings of the Society for Experimental Biology and Medicine, 68, 1.

Sokoloff, L., and Gleason, I. O. (1954): The Sternoclavicular Articulation in Rheumatic Diseases. American Journal of Clinical Pathology, 24, 406.

WAALER, E. (1940): On the Occurrence of a Factor in Human Serum Activating Specific Agglutination of Sheep Blood Corpuscles. Acta Pathologica et Microbiologica Scandinavica, 17, 172.

Vol. 41 B, NO. 4, NOVEMBer 1959 